\title{
Interactive Multimedia Instruction in Video Production Classes
}

\author{
Timothy J. Hudson and SieILA DENISE Holland
}

Students who enroll in a video production class at a typical college are required to buy a textbook, sometimes a workbook, and usually several video tapes. Conscientious students reads the textbook. They also use the workbook to reinforce what they have read and may choose to look up some of the other books or articles referred to by the textbook. They go to class and hear a lecture from a qualified professor. The professor may use other means at his or her disposal as well, such as drawing on the chalk board, class discussion, and even a video tape on the subject at hand. Then the students go to lab, where they see the lesson put to use and finally get to put it all to use themselves.

Suppose however, that any student could have the textbook, the workbook, extra reference books and articles, lectures from many different professors, drawings, still pictures, video, and even a certain amount of discussion at his or her fingertips daily-all in one compact workstation. No longer is the student a passive learner. Nor must the student work long and hard to assemble extra sources for added understanding.

There is a tool available that makes all this possible. This tool goes by many names, including hypermedia (Marchionini, 1988), interactive video (Baron \& Hutchinson, 1984), interactive videodisc (Meyer, 1984), interactive video systems (Seal-Wanner, 1988) and interactive multimedia (Savenye, 1990). The names have changed along with the growth of the system. Because of the vast amount of information available to students through a multitude of media in today's interactive system, interactive multimedia is probably the most appropriate term.

The purpose of this study is to evaluate the performance of interactive multimedia in a video production class. The experiment evaluates interactive multimedia's effectiveness compared to the typical classroom lecture. Interactive multimedia (IAM) is the non-linear combination of graphics, sound, animation, text, pictures, and video clips that takes advantage of the computer's ability for random access (Marchionini, 1988; Corcoran, 1989).

Interactive multimedia has many features and advantages which make it most appealing to the many people and institutions experimenting with it. Students have access to a large amount of information stored compactly for rapid and easy access and presented in a variety of media.

Osborn (1990,p. 370), maintains that

Hudson is assistant professor and Holland is a former adjunct instructor of journalism and mass communication at the University of Oklahoma. 
the most significant feature of IAM is its ability to "... deliver extraordinary depth of experience without the user running out of material after a few hours of involvement." Furthermore:

- Students and teachers have the capability of editing and updating this information to suit their own needs.

- IAM enables teachers and students to express their ideas much more clearly and in more detail (Marchionini, 1988; Nanny, 1990; Osborn, 1990). The interaction between students and teachers becomes richer and more challenging (Marchionini, 1988).

- IAM also has the ability to enhance the relationships among students.

- Through networking-the linking of computers-students are given access to as much material as they desire as well as to the thoughts and conclusions of other students following their same journey (Osborn, 1990)

One of the strongest advantages that IAM offers the educational system as a whole is its flexibility. It can be shaped to meet the needs of different students and their different learning styles (Seal-Wanner, 1988). Teachers can customize programs to meet the needs of certain individuals or groups. They can design programs for use by individuals, small groups, or whole classes (Atkins, 1989; Baker, 1988; Cole, 1988). Best of all, IAM presents information in a number of media, thus involving students aurally, visually, and kinetically (Hudson, 1990 ).

Researchers have grouped students into categories according to how they learn best. The auditory or verbal group uses the ears as the favorite information receiver. Visual or spatially oriented people tend to learn best what they see or can visualize. Kinetic or kinesthetic people learn best what they touch, feel, or experience. Vision is the primary sense for most people, so it is generally believed that people tend to learn best with their sight. Often, verbal explanations must be complemented with visual explanations before an understand- ing is reached.

One of the most recognized factors influencing the learning of students is the physiological factor. It may be of little surprise that males and females do not learn in the same ways. Females tend to be more sensitive to sounds and touch. They tend to be more verbal and to exceed males in language capabilities. However, males generally show a visual superiority to females. They are more curious and they often relate to inanimate objects as quickly as to people.

These differences often put males at a disadvantage in the classroom, where they are forced to sit still, listen to the teacher, and express themselves in writing, but at an advantage on standardized tests, which often emphasize math and science (Keefe, 1979; Restak, 1979). Males may also be at an advantage with interactive multimedia. According to Atkinson (1977), while both boys and girls benefit from using computer-assisted instruction, boys benefit more.

Since IAM is little more than the combination of computer-assisted instruction (CAI) and video, and since boys are also visually superior to girls, evidence suggests that males will also benefit more from IAM than do females. IAM tools are not used exclusive of one another. When one modality is reinforced by another, learning is enhanced for both sexes. (Schultz \& Schultz, 1989).

When a teacher matches his or her teaching style to that of the learning style of a student, it produces significant academic gains (Dunn, Dunn \& Price, 1979). Therefore, today's educators are seeking to develop curricula that will best benefit a greater number of children. Since students learn through their senses, the best method would include all the modalities. IAM incorporates most of these modes of learning and therefore has the ability to tap into each of these intelligences (Jenkins, 1990; Semper, 1990).

Experimentation with IAM has been 
ongoing for several years. Zan Bailey (1990), educational computer consultant at $\mathrm{Mi}$ ami-Dade Community College in Miami, Fla., conducted an experiment to determine the effectiveness of both interactive multimedia and CAI. He found that "Students who utilize optional educational media in the form of computer-only and interactive video computer-assisted-instruction in conjunction with conventional classroom instruction will achieve higher College Level Academic Skills Test (CLAST) scores than students receiving only conventional classroom instruction" (p. 82). Both IAM and CAI seemed to benefit those students who used them. Students who used both IAM and CAI scored highest. Students who used IAM, but not CAI, scored next highest, and those students using only CAI scored third (Bailey, 1990).

Many of the studies conducted showed that students learn faster, make higher test scores, retain more information, and enjoy using interactive video more than they do in a typical class (Petty \& Rosen, 1987). A study conducted at the University of Alabama found that accounting students who used IAM not only scored higher on their final exam, but also noted enjoying the class more than usual. Another study found that thirty minutes of IAM instruction is roughly equal to ten to fifteen hours of student study (Petty \& Rosen, 1987).

Groups other than educational institutions are experimenting with IAM, including the military. In one such study, researchers found that the IAM techniques significantly reduced training time. Also, while the initial testing of the trainees found no significant difference in scores between the experimental and control groups, a delayed post-test did find that the experimental group scored significantly higher. Both the instructors and the students responded more favorably to the interactive program than to the traditional one (Ebner, Manning, Brooks, Mahoney,

\section{Lipert \& Balson, 1984).}

Experimentation with IAM should take place on many levels and in many different areas, including mass communication. Perhaps video production teachers and students should lead the way in the development of IAM. Interactive programming will be a major portion of the work done by media developers in the near future. Video students should be a target market for learning through IAM (Hudson, 1991). Many mass communication professors want their students to be involved in the development and writing of interactive programs. Several courses could cultivate their individual skills and then combine them with each other for a collective programming experience (Vogel, Shulman \& Jenisch, 1990).

This project examines the relationship between student use of interactive multimedia and their retention of information. It will also facilitate a look at the relationship between IAM and the students' enjoyment of their lesson and their perceptions of how much they have learned. Goals of the study are very specific.

\section{Hypotheses}

1. Students using the interactive multi media system to learn the lesson will score higher on curriculum posttests than will students who received the lesson in the typical classroom lec ture manner.

2. Males using the interactive multime dia system will score higher on cur riculum posttests than will females who used the interactive multimedia system.

3. Students using interactive multime dia will indicate that they enjoyed the lesson more than previous lessons.

4. Students who receive the lesson in the typical classroom lecture will in dicate that they enjoyed the lesson about the same as other lessons.

5. Students using interactive multime 
dia will indicate that they enjoyed the lesson more than the lecture students will indicate that they enjoyed it.

6. Students using interactive multime dia will perceive that they learned more with this lesson than with pre vious lessons.

7. Students attending the classroom lec ture will perceive that they learned about the same amount as usual in previous lessons.

8. Students using interactive multime dia will perceive that they learned more than the lecture students will perceive that they learned.

\section{Method}

The purpose of the experiment was to determine the effectiveness of IAM as a tool for teaching certain lessons in an Introduction to Video Production class. The specific lesson chosen for experimentation involved lighting techniques for video production. The class was divided into two groups, of which one used IAM.

The basic interactive multimedia system consists of a personal computer, a television monitor (if the computer screen cannot double as the video monitor), and either a video disc player or a videocassette recorder (Baron \& Hutchinson, 1984). The hardware used in this research included a Macintosh computer, a Sony VHS videocassette recorder, and a television monitor.

In the case of this experiment, the lesson revolved around two sources. The bulk of the information was taken from the students' textbook, Television Production Handbook by Herbert Zettl. All of the video was from an educational videotape titled "Lighting in the Real World." In most cases, the video was used to reinforce information presented by the book.

\section{Procedure}

Students in two sections of the course, "Introduction to Video Production" were randomly assigned to one of two groups, a control group, and an experimental group. There were, however, some unexpected scheduling conflicts with some subjects in the experimental group. The total control group for this experiment consisted of forty-nine students while the total experimental group consisted of thirtynine students.

The experiment was conducted over a three-week period. The class only met once a week for lecture. The first week all of the participants took a short pretest during lecture time. The second week all members of the control group attended lecture as usual while the members of the experimental group chose an alternative hour during that week to spend on the interactive multimedia system. The third week all of the participants took a posttest, which was exactly the same as the pretest, with a few additional questions regarding their perceptions of the lesson itself.

The author of the interactive program conducted the lecture, using the same material included in the interactive program. Care was taken to include as many different media as possible in the lecture in order to decrease the media gap between the IAM system and the lecture. The lecture included portions of a videotape, drawings on the chalk board and references to the textbook. The lecture plus time for questions lasted the entire fifty minutes allotted for the class.

Students in the experimental group met in an assigned area in groups of three. The three people were then separated and worked at individual interactive kiosks, each in a different room. They were instructed to enter their names through the computer keyboard, but after that the only input device used was the mouse. The instructions were included in the program, so the instructor left the room and only returned occasionally to see that the program was progressing smoothly.

Students were limited to the same time frame used by the lecture students, but only four students required the entire 


\section{TABLE 1 \\ Frequency Distributions OF THE ENJOYMENT RATING}

$\begin{array}{cc}\begin{array}{c}\text { Experimental Group }(\text { Mean }=4.8) \\ \text { Interactive Multimedia }\end{array} \\ { }^{*} \text { Rating } & \text { Frequency } \\ 0 & 1 \\ 1 & 0 \\ 2 & 1 \\ 3 & 3 \\ 4 & 6 \\ 5 & 16 \\ 6 & 11\end{array}$

Control Group $($ Mean $=3.6)$ Lecture

$\begin{array}{cc}* \text { Rating } & \text { Frequency } \\ 0 & 0 \\ 1 & 1 \\ 2 & 8 \\ 3 & 17 \\ 4 & 12 \\ 5 & 8 \\ 6 & 3\end{array}$

${ }^{*}$ A rating of zero indicated the student enjoyed the lesson much less than usual, a rating of three indicated the same as usual, and a rating of six indicated much more than usual.

fifty-minute period. The average amount of time spent on the interactive multimedia program was approximately thirty minutes. Students were allowed to leave after completion of the program.

The interactive program included portions of the lighting videotape, graphics, animation, music, and text. The same material was covered in both groups, but the experimental group was given the opportunity to explore some additional information if they so desired. Outlines of the lecture, the interactive multimedia program, copies of the pretest and posttest, as well as flowcharts of the computer pro- gram are available from the authors.

The lecture was conducted on a Monday. Members of the experimental group completed the program between Monday and Wednesday.

\section{Results}

In order to test the hypotheses, a combination of t-tests and frequency distributions were performed.

Hypothesis 1 stated that students using the interactive multimedia system would score higher on the posttest than would the students in the lecture. The first step toward an answer was to determine if the control group pretest scores were significantly different from the experimental group pretest scores. T-tests between these groups indicated that the difference was not statistically significant ( $p>.05$ ).

Next, it was important to discover if both groups made significant increases between the pre- and posttests. Results of t-tests conducted on the control group's pre- and posttest scores and the experimental group's pre- and posttest scores show that in both cases the increase was significant $(p<.05)$.

Finally, in order to determine if Hypothesis 1 was or was not supported, a ttest was applied to the posttest scores of the control and experimental groups. The $\mathrm{t}$-score was not statistically significant at the .05 level. Therefore, it could not be concluded that students using interactive multimedia scored higher on the posttest than students who went to the lecture.

Hypothesis 2 stated that males using IAM would score higher on the posttest than females who also used IAM. First, comparisons were made to ensure that both groups scores increased from pre- to posttest. Then, the posttest scores of both groups were compared to see the significance of the difference .

The increase in the pre- and posttest scores for the males was significant at the $(p<.05)$, with a $\mathrm{t}$-score of -8.18 . The increase for the females was also significant 
at the .05 level, but the t-score was only 5.17. It would appear that the males made more progress than the females. According to the t-test there was a statistically significant difference at the .05 level between the posttest scores of the males and females. Therefore, the hypothesis that males using IAM would score higher on the posttest than females using IAM was supported.

Hypothesis 3 stated that students using IAM would indicate that they enjoyed the lesson more than previous lessons in that class. Hypothesis 4 stated that lecture students would rate the lesson about the same as usual. In order to test these hypotheses, frequency distributions and mean scores were calculated (see Table 1). The scale students used to rate their enjoyment was from zero to six. A rating of zero indicated the student enjoyed the lesson much less than usual, a rating of three indicated that the student enjoyed the lesson the same as usual, and a rating of six indicated that the student enjoyed the lesson much more than usual.

The mean score for the experimental group was 4.8 and the frequency distribution indicated that the scores clustered around the ratings 5 and 6 . This would indicate that the students who used IAM enjoyed the lesson more than previous lessons, thus supporting Hypothesis 3 . The mean score for the control group was 3.6 and the frequency distribution indicated that the scores clustered around the ratings 3 and 4 . This would indicate that the students who attended the lecture enjoyed the lesson about the same as previous lessons, thus supporting Hypothesis 4.

Hypothesis 5 compared the IAM group's rating with that of the lecture group. In order to accomplish this, a t-test was conducted. The t-score was -4.6 which is significant at the .05 level of acceptance. Therefore, Hypothesis 5, which stated that students using IAM would indicate that they enjoyed the lesson more than the lecture students would indicate they en- joyed the lesson, is supported.

Hypothesis 6 stated that IAM students would perceive that they learned more using IAM than in previous lessons. Hypothesis 7 stated that lecture students would perceive that they learned about the same as usual. As with Hypotheses 3 and 4 , frequency distributions were conducted and the mean scores were calculated (see Table 2). The mean score for the experimental group was 4.7 and the frequency distribution indicated a cluster around the ratings 4,5 and 6 . While not as clear as the enjoyment rating, this indicates that the experimental groups perceived that they

\section{TABLE 2}

\section{FrequenCy Distributions of the Perceived Learning Rating}

\begin{tabular}{|c|c|}
\hline \multicolumn{2}{|c|}{$\begin{array}{l}\text { Experimental Group (Mean }=4.7 \\
\text { (Interactive Multimedia) Group }\end{array}$} \\
\hline${ }^{\star}$ Rating & Frequency \\
\hline 0 & 0 \\
\hline 1 & 1 \\
\hline 2 & $\mathbf{0}$ \\
\hline 3 & 1 \\
\hline 4 & 13 \\
\hline 5 & 15 \\
\hline 6 & 9 \\
\hline Contr & $($ Mean $=4.1)$ \\
\hline${ }^{*}$ Rating & Frequency \\
\hline 0 & 0 \\
\hline 1 & 1 \\
\hline 2 & 1 \\
\hline 3 & 13 \\
\hline 4 & 15 \\
\hline 5 & 14 \\
\hline 6 & 5 \\
\hline
\end{tabular}

${ }^{*}$ A rating of zero indicated the student per ceived he or she learned much less than usualfrom the lesson, a rating of three indicated the same amount as usual, and a rating of six indicated much more than usual. 
learned more from the IAM lesson than previous lessons, thus supporting Hypothesis 6.

The mean score for the control group was 4.1 and the frequency distribution indicated a cluster around the ratings 3,4 and 5 . Once again, this is not as clear as the enjoyment ratings were, but considering that both three and four indicate a rating of "about the same," it can be tentatively concluded that students in the lecture group perceived that they learned about the same as with previous lessons, thus supporting Hypothesis 7.

Hypothesis 8 compares the ratings of the two groups. A t-test was conducted resulting in a t-score of -2.7 which is statistically significant $(p<.05)$. Therefore, Hypothesis 8 , which posited that students using IAM would perceive that they learned more than the lecture students would perceive that they learned, is supported.

\section{Discussion}

Students using the interactive multimedia system did not score higher on the posttest than those students who attended the lecture. These results are not in agreement with findings from the research conducted by Bailey (1990), Laurillard (1984), Browning, White, Nave and Barkin (1986), Ebner et al. (1984) and many others. Each of these studies found significant gains in the amount students learned through interactive multimedia. So much research has been done to support the findings of both groups of researchers that one finding with opposing results does not necessarily question the validity of those studies. This study should be refined, replicated, and expanded.

The makeup of the lecture itself may have skewed the findings in this experiment. In order to guarantee that the information received by the control group students and the experimental group students was the same, every effort was made to include several different media in the lecture. Portions of the videotape used in the interactive system were shown to the control groups, as well as drawings on the chalkboard and pictures from the book. These items are not always included in a typical lecture, and the effort to keep the lecture similar to the program may have confounded the results by giving lecture students a higher multimedia experience than usual.

Ebner, et al. (1984), are quick to point out that the lack of a valid significant difference does not necessarily mean that the tested technology does not offer benefits. A result of no difference may prove useful if the technology does offer something that the current system does not. For example, if the technology offers the same amount of information for less money or if students enjoy it more than the typical system, then the study could still produce positive results. Therefore, even though this study does not support the hypothesis that students learn better with interactive multimedia, the fact that the students did not learn less may actually be a positive result. For one thing, students learned as much with 30 minutes of IAM as in 50 minutes of lecture.

The second hypothesis had more favorable results. As it stands, females tend to benefit more from lectures than males, due to the learning differences between the sexes. However, IAM could be the tool that equalizes this bias by allowing males to learn in a manner that is more appropriate for them. Also, if IAM programs are designed with both visually and auditorally oriented students in mind, it could be just as beneficial for both men and women.

Hypotheses 3, 4, and 5 dealt with the issue of students' perceived enjoyment of the traditional lecture as opposed to the interactive system. This is a significant finding because research indicates that enjoyment is one step toward motivation (Frenkel, 1989; Osborn, 1990). Even though IAM may not have increased the overall scores of all the students any more than the lecture did, it may be enough of a motivator 
to provide some long range advantages, such as increased participation by students in their learning, and perhaps eventually test scores would rise accordingly.

Finally, Hypotheses 6, 7, and 8 considered students' perceptions regarding the amount they learned. First, it was necessary to determine whether the IAM students believed they learned more than in previous lessons. The results of Hypothesis 6 support that notion. Lecture students perceived that they learned about the same as usual.

The difference between the IAM and the lecture groups was significant, indicating that even though IAM students did not necessarily learn more, they believed they had. This could be very important because, as Keefe (1979) points out, students who expect to do better are often motivated to do better. If students were to believe that they were learning more while in fact they were not, this could give them a false sense of security. Instead of motivating students to do more and better work, it could lead them to believe that IAM will do all the work for them.

\section{Conclusions}

While the findings of this study are very limited and specific, they do indicate some areas that need further research. The findings suggest that in the area of video production, some lessons lend themselves more to IAM than do others.

Determining which lessons are more appropriate for IAM could add to IAM's effectiveness in video production education. For example, do the lessons that involve picturization lend themselves more to IAM as a medium than lessons that do not require students to visualize what they are learning?

Another question to be considered is whether or not video production students might enjoy interactive multimedia more than other students, considering they are enrolled in a video oriented class, and perhaps are more interested in video than the typical student.

More research needs to be conducted concerning the effect IAM has on the ways that males and females learn. If, in most cases, males do tend to learn better with IAM, what does this indicate about the way programs should be designed? An effort should be made to determine what is necessary in order to make IAM equally beneficial to females.

Motivation is seen as a serious factor in this study, leading to even more questions. Does IAM work better for those students who are less motivated? Perhaps interactive multimedia helps motivate students to learn, and if so, it may increase the amount of learning that actually takes place. It may also encourage students' participation in their education. This leads to the question of motivation's link to higher test scores.

Perhaps future research should also consider the question of grades. Do students who tend to score lower grades receive more help from IAM than do students who score average or better grades? Or are the above-average students apt to learn even more by taking advantage of the many branching and interactive possibilities?

Experimentation needs to concentrate more on the length of retention when students are taught with IAM. Students learn faster through interactive multimedia, but do they retain information longer than students who do not use IAM?

Most of the comparative research concludes that IAM provides a greater learning environment than traditional, linear teaching. While this study does not corroborate those findings with a result of increased retention, this study does provide some insight into the interactive multimedia picture. This picture is one of equalization, motivation, and participation in education-three very good reasons why interactive multimedia belongs in the hands of today's media educators. $\square$ 
Atkins, M. (1989, May 5). Visual stimulus. The Times Educational Supplement, p. B30.

Atkinson, R. C. (1977). Teaching children to read using a computer. In M. C. Wittrock (Ed.), Learning and instruction (pp. 570-585). Berkeley, California: McCutchan Publishing Corporation.

Bailey, Z. T. (1990). CAI and interactive video enhance students' scores on the college level academic skills test. T. H. E. Journal, 17 (5), 8285.

Baker, P. (1988, November 11). Interactive video the made-to-measure medium: What's that? The Times Educational Supplement, p. 59.

Baron, Jr., A. \& Hutchinson, J. (1984). Interactive video: A promising technology for counseling services. Journal of Counseling and Development, 63 (4), 244-247.

Browning, P., White, W. A. T., Nave, G., \& Barkin, P. Z. (1986). Interactive video in the classroom: A field study. Education and Training of the Mentally Retarded, 21 (2), 85-92.

Cole, G. (1988, November 25). Exploding on to the scene. The Times Educational Supplement, p. 35

Corcoran, E. (1989, July). Science and business: Show and tell. Scientific American, pp. 72-74.

Dunn, R., Dunn, K., \& Price, G. E. (1979). Identifying individual learning styles. In Student learning styles: Diagnosing and prescribing programs (pp. 39-54). Reston, Virginia: National Association of Secondary School Principals.

Ebner, D. G., Manning, D. T., Brooks, F. R., Mahoney, J. V., Lippert, H. T., \& Balson, P. M. (1984, September). Videodiscs can improve instructional efficiency. Instructional Innovator, 29, 26 28.

Frenkel, K. A. (1989). The next generation of interactive technologies. Communications of the $A C M, 32$ (7), 872-881.

Hudson, T. J. (1990, March). Computer-interactive media in video production education: Embracing the technology. Paper presented at the meeting of the Broadcast Education Association Convention, Atlanta, Georgia.

Hudson, T. J. (1991). Viewpoint: State of the art capabilities are necessary. Feedback, 32 (3), 20.

Jenkins, Y. (1990). Multimedia technology: Tools for early learning. In S. Ambron \& K. Hooper (Eds.), Interactive Multimedia (pp. 113-123). Redmond, Washington: Microsoft Press.
Keefe, J. W. (1979). Learning style: An overview. In Student learning styles: Diagnosing and prescribing programs (pp. 1-17). Reston, Virginia: National Association of Secondary School Principals.

Laurillard, D. M. (1984, June). Interactive video and the control of learning. Educational Technology, $24,7-14$.

Marchionini, G. (1988). Hypermedia and learning: Freedom and chaos. Educational Technology, 28 (11), 8-12.

Meyer, R. (1984). Borrow this new military technology, and help win the war for kid's minds American School Board Journal, 71 (6), 23-28.

Nanny, M. (1990). Interactive images for education. In S. Ambron \& K. Hooper (Eds.), Interactive Multimedia (pp. 87-98). Redmond, Washington: Microsoft Press.

Osborn, H. (1990). Media computers, motivation, and informal education: Gutenberg 2000? In S. Ambron \& K. Hooper (Eds.), Interactive Multimedia (pp. 359-381). Redmond, Washington: Microsoft Press.

Petty, L. C. \& Rosen, E. F. (1987). Computer-based interactive video systems. Behavior Research Methods, Instruments, \& Computers, 19 (2), 160166.

Restak, R. M. (1979). The other difference between boys and girls. In Student learning styles: Diagnosing and prescribing programs (pp. 75-80). Reston, Virginia: National Association of Secondary School Principals.

Savenye, W. (1990, April). Developing interactive multi-media programs for teaching: Trends and issues. A colloquium sponsored by the Educational Technology Program Area and the Department of Educational Psychology, The University of Oklahoma.

Schultz, T. \& Schultz J. (1989). Do it! Active learning in youth ministry. Loveland, Colorado: Group Books.

Seal-Wanner, C. (1988). Interactive video systems: Their promise and educational potential. Teachers College Record, 89 (3), 373-383.

Semper, R. (1990). Hypercard and education: Reflections on the hyperboom. In S. Ambron \& $\mathrm{K}$. Hooper (Eds.), Interactive Multimedia (pp. 53-67). Redmond, WA: Microsoft Press.

Vogel, R. A., Shulman, G. M. \& Jenisch, R. A. (1990). Teaching interactive video: A team approach. Feedback, 31 (2), 22-23. 